\title{
El fractal como paradigma arquitectónico: deconstrucción vs lenguaje de patrones vivientes
}

\author{
The fractal as an architectural paradigm: deconstruction vs. living patterns \\ language
}

Joely Ariagny Sulbarán Sandoval, ${ }^{1}$ M.Sc.

${ }^{1}$ Universidad del Zulia, Área de investigación eficiencia energética, Línea de investigación Vivienda y Hábitat. Venezuela. Correspondencia: joelysulbaran@gmail.com.

Recibido: 27 de marzo de 2016. Aceptado: 16 de mayo de 2016.

Sulbarán, J. (2016) El fractal como paradigma arquitectónico: deconstrucción vs lenguaje de patrones vivientes. Procesos urbanos Número 3, Ene-Dic. 79-88. Doi:10.21892/2422085X.268

\section{RESUMEN}

El presente estudio tiene como objetivo principal el estudio de la teoría fractal como nuevo paradigma en la Arquitectura, con el interés de fijar una posición reflexiva de la habitabilidad corporal-espacial de los seres humanos, cuyo comportamiento es de tipo fractal debido a la diversidad y a la incertidumbre que representa cada individuo. La metodología del estudio es de tipo documental no experimental, basada en la revisión de literatura concerniente al estudio de sus principales teorías, como son la teoría fractal, el deconstructivismo y el lenguaje de patrones vivientes, así como sus características, principales exponentes y teorías respectivas. La presente investigación considera que es importante la necesidad de que la arquitectura vuelva a su principio antropocéntrico, en el que el satisfacer las necesidades humanas sea su principal objetivo, para generar arquitectura más humana, al comprender y producir complejidad que responda a la diversidad cultural-corporal y permitir así un desarrollo emocional-corporal en los espacios.

Palabras clave: Fractal, deconstructivismo, lenguaje de patrones vivos, habitabilidad

\section{ABSTRACT}

The present study has as main objective the study of the fractal theory as a new paradigm in Architecture, with the interest of fixing a reflexive position of the physical-space habitability of human beings, whose behavior is fractal type due to the diversity and the uncertainty that each individual represents. The methodology of the study is non-experimental documentary, based on the literature review concerning the study of its main theories, such as fractal theory, deconstructivism and the language of living patterns, as well as its characteristics, main exponents and respective theories. The present research considers that it is important that architecture return to its anthropocentric principle, in which satisfying human needs is its main objective, to generate more human architecture, to understand and produce complexity that responds to cultural- Body and allow an emotional-corporal development in the spaces.

Keywords: Fractal, deconstructivism, language of living patterns, habitability 


\section{INTRODUCCIÓN}

Ahora mismo la nueva ciencia y sus principales precursores se encuentran en un periodo de redescubrimiento y de revalorización de los seres humanos, en aras de mejorar su calidad de vida. Teorías como la complejidad, geometría fractal, teoría del caos, entre otras, colocaron en tela de juicio la ciencia clásica al demostrar que la realidad es provisional, parcial y coyuntural; que no es posible conocer la totalidad de un objeto, que la totalidad es más que la suma de las partes y que la linealidad no existe, sino segmentos de recta que forman partes de macro curvas. Del mismo modo se puede afirmar que el proceso de vida es imparable y está en vuelto en constante incertidumbre, confusión y desorden aparente. (Pineda 2009), (Martin 2008). Por tal razón los científicos, matemáticos y filósofos como Prigogine, Morín, Mandelbrot, Alexander, entre otros, han trabajado desde la teoría del caos creada por Prigogine, demostrando que todo caos tiene su orden y tiene unos parámetros que sigue, un ritmo, repetición, y conectividad, esto puede verse reflejado en la naturaleza como bien lo dice Mandelbrot.

Vale destacar que a raíz de todos los usos y abusos (ensayo y error) de la ciencia clásica, la nueva ciencia se plantea como objetivo principal un equilibrio entre fines y medios que permita el empleo de las tecnologías (herramientas) para el propósito que fueron creadas y no como el fin último de la ciencia; todo esto es el resultado de la reflexión crítica de los acontecimientos generados por la falta de ética y en muchos casos, por ignorancia de los seres humanos de cómo deberían reaccionar a esta progresiva e inequitativa evolución.

Por su parte, la arquitectura ha tenido un sin número de exponentes y de nuevas tendencias influenciados por la globalización y de las nuevas tecnologías sobre todo en las últimas décadas, y esta se ha ido desarrollando conforme con las necesidades de las sociedades, sus modos de vida y su cultura, al mismo tiempo basada en algunos casos en los nuevos conocimientos de la ciencia.
Buscando responder de la manera más adecuada y lograr los mejores resultados, se han establecido relaciones entre la arquitectura con las nuevas ciencias, y por consiguiente se ha reflexionado sobre la complejidad que representa el edificar, los factores, los actores, las necesidades y la manera más conveniente de solucionarlas, que permitan el habitar de los espacios arquitectónicos, a raíz de estas concepciones teóricas, que han generado infinidad de perspectivas para garantizar no solo la habitabilidad de las edificaciones, sino el buen desempeño de las mismas en el contexto urbano y ambiental.

De tal forma el empleo de las nuevas ciencias en la construcción arquitectónica, según Salíngaros (2004), puede ser de múltiples puntos de vista, no obstante los dos puntos de vista más radicales en el uso de la teoría fractal, son las tendencias deconstructivistas de las que habla Jencks (2003) en su libro "Arquitectura fractal".

Según Jencks, citado por Salíngaros (2004), el nuevo paradigma en la Arquitectura es la deconstrucción, de la mano de los arquitectos Peter Eisenman, Frank Gehry, y Daniel Libeskind, Zaha Hadid, entre otros, los cuales son reconocidos internacionalmente por sus obras monumentales, productos intencionales de la interrupción de los procesos de continuo despliegue, una manipulación geométrica interesante, lo que trae como resultado una casualidad azarosa según Salíngaros, que muchas veces es disfuncional.

Adicionalmente menciona Salíngaros que estos edificios deconstructivistas, no se adaptan a las necesidades humanas y que solo son regidos por inquietudes únicamente formales. Por el contrario, lo que considera el autor como verdaderamente un nuevo paradigma en arquitectura y realmente está enfocado en la ciencia, teniendo particularidades para considerarla fractal, es la arquitectura realizada a partir de las teorías de Christopher Alexander, arquitecto y científico que en la época de los 70 y 80, logró aproximarse a una definición de arquitectura humana, a través del uso de patrones de acontecimientos o patrones vivos como él mismo decía. 
En la presente investigación se pretende subrayar que el objetivo de la arquitectura, sin importar la postura del arquitecto, es el habitar. La satisfacción corporal-mental del habitante, debe ser primacía del arquitecto y de la arquitectura. La habitabilidad es la característica que le da el sentido de arquitectura a las construcciones y a las propias ciudades, siempre enfocada en el ser humano que ocupa los espacios.

\section{¿QUÉ ES UN FRACTAL?}

Anteriormente todas las formas eran calculadas mediante el uso de la geometría basados en el punto, la recta y la superficie, medidas solo en números enteros, las formas o medidas que fueran fraccionarias pertenecían a las ecuaciones no lineales, las cuales casi nunca eran tomadas en cuenta, no había el conocimiento para abordarlas en la ciencia clásica, la cual siempre quería tener el control total. Las formas irregulares forman parte de un caos o incertidumbre que la ciencia clásica no podía controlar. La no linealidad constituye el lenguaje del caos. Sin embargo, la naturaleza está compuesta por múltiples formas que permiten su singularidad, irregularidad y perfección; por tal razón muchas veces es llamada divina. El ejemplo más impresionante es el de un árbol, su forma irregular que a la vez es una repetición de la misma forma a diferentes escalas, que generan un orden jerárquico, como es el caso de tallo, las ramas, las hojas, repitiéndose infinitamente, y así muchas formas en la naturaleza, tales como, las grietas en la corteza de los árboles, las montañas, las nubes, las costas, hasta los pulmones humanos, el cerebro, entre otras. Estas estructuras complejas y fraccionarias pertenecen a los llamados fractales.

Según Mandelbrot, citado por Pineda (2009), el término fractal proviene de la palabra latina "fractus", entendida como parte o fracción y de "rangere" que significa romper. Se relaciona con la dimensión fraccionaria. Los fractales son curvas infinitas contenidas en una superficie finita, por lo tanto se expresan como número de dimensiones, no entero o fragmentario.
De igual forma, Mandelbrot considera que los fractales son objetos geométricos curiosos, generados por la interación infinita de un algoritmo bien especificado. La dimensión de un fractal es fraccionaria. El fractal es matemáticamente una figura geométrica que es compleja y detallada en estructura a cualquier nivel de magnificación. Dentro de un fractal el orden y el caos están en perfecta armonía.

Asimismo las estructuras fractales presentan ciertas propiedades que los identifican, como lo son: 1. Repetición infinita de la misma forma; 2. Valores fraccionarios; 3. Conjuntos que surgen a través de procesos iterativos infinitos; 4 . Se puede aplicar a cualquier escala, ya sea macro o micro; 5 . Conectividad; 6 . Estructura jerárquica.

Según Pineda (2009), lo trascendente del procedimiento es que desvela un mundo rico, complejo y creativo, mediante la interación de ecuaciones matemáticas sencillas, que según Briggs (1992) son esencia, formulaciones simbólicas de la lógica humana.

Por su parte Salíngaros (2004), agrega que el fractal es la periodicidad que genera una jerarquía, anidada de conexiones internas. Una línea fractal, una estructura de un grano extremadamente fino. El fractal contribuye al establecimiento de un nuevo enfoque de la ciencia, que genera nuevos conocimientos y múltiples formas de enfrentar la realidad cambiante y fluida. Este nuevo mundo que nos permite conocer la geometría fractal es un mundo más complejo, lleno de relaciones y de multiplicidades, diverso e interconectado, más amplio del que se lograba determinar con la ciencia clásica. (Bauman 1999, Mandelbrot, 1975, Morín 1999)

Vale destacar que el paradigma fractal ha sido empleado en otras disciplinas de la ciencia, como en la biología, la geografía, la medicina, la astronomía, entre otras, donde la arquitectura se ve envuelta a través de su increíble manipulación geométrica y en algunos casos en la búsqueda de nuevas alternativas a las relaciones de conectividad no solo a nivel arquitectónico, sino también urbano. 


\section{Procesos Urbanos N³ Enero - Diciembre; 2016}

\section{EL FRACTAL Y SU INTERPRETACIÓN EN LA ARQUITECTURA}

Por lo que se refiere a la fractalidad arquitectónica, existen muchas interpretaciones, cada exponente defiende su punto de vista como la postura más cercana para lograr dicha propiedad en arquitectura y el urbanismo. Hay autores que expresan su inclinación hacia una teoría de las formas geométricas, expresada mediante estructuras llamativas, empleo y disposición de elementos similares a los logaritmos, repeticiones, formas abstractas e irreverentes. Por el contrario, existe la postura de los que se oponen a estas teorías formales, quienes afirman que la fractalidad de las edificaciones es generada a través la aplicación de las ciencias humanas, tratando de dar respuestas más efectivas y comprometidas con las necesidades, así mismo aplicado al urbanismo de las ciudades, precisamente en los nodos, conexiones y jerarquía.

A continuación se presentan dos posturas contradictorias en cuanto a la arquitectura fractal, como lo son la arquitectura deconstructivista y la arquitectura basada en el lenguaje de patrones.

\section{Postura Deconstructivista}

La postura deconstructivista, pensamiento concebido por el filósofo francés Jack Derrida. Su conocimiento fue influenciado desde su juventud por el filólogo Ferdinand de Saussure y los filósofos Nietzeche, Freud y muy especialmente por Martín Heidegger, autor del libro "Sery Tiempo"del cual proviene la palabra alemán Destruktion la cual le dio origen, según Derrida a la palabra deconstrucción (Reyes 2005).

Se puede señalar que la deconstrucción es un tipo de pensamiento que critica, analiza y revisa fuertemente las palabras y sus conceptos. La teoría o pensamiento deconstructivista pone en evidencia la incapacidad de la filosofía clásica de establecer un piso estable, sin dejar de reivindicar su poder analítico. Cabe mencionar que la mayoría de los estudios de Derrida exponían una fuerte dosis de rebeldía y de crítica al sistema social imperante.

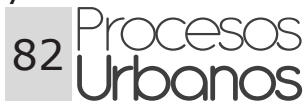

Según Derrida, citado por Reyes, la deconstrucción es, "Uno de los nombres posibles para designar, por metonimia, lo que sucede o lo que no llega a suceder, como lo puede ser una cierta dislocación que se repite regularmente".

Por su parte, la arquitectura deconstructivista según Jencks es el nuevo paradigma, de la mano de Peter Eisenman, Frank Gehry , Daniel Libeskind, Zaha Hadid; entre otros. Según Jencks (2003), las obras de los arquitectos deconstructivistas están basadas en las leyes de las nuevas ciencias, como es el caso de la complejidad, los fractales, los procesos emergentes, la autoorganización y la similaridad. Aun cuando el mismo Jencks expresa que más que la creación de fractales a través de la deconstrucción, lo que se quiere es responder a estructuras formales y darles expresión dinámica.

Con respecto a lo que se puede observar a simple vista, en las edificaciones de los ya nombrados arquitectos deconstructivistas es importante resaltar el uso de materiales HighTech, en muchos casos formas geométricas simples (paralelepípedos) aunados a figuras irregulares con materiales totalmente contrarios que generan fuertes contrastes visuales, que rompen con todo el contexto y son los protagonistas de los espacios; otros por el contrario son exclusivamente hechos de formas irregulares extravagantes y muy elaboradas, repetición de formas, estructuras dentadas, manipulación asombrosa de las formas curvas y oblicuas, manejo de las inclinaciones en los pisos y entre pisos, entre otras cualidades y deformaciones.

Seguidamente en las imágenes 1 a la 4 se puede ver cómo estos arquitectos emplean el uso de módulos repetidos en gradación de tamaño que sugieren ese movimiento y dinamismo de las mismas, el uso de planos inclinados que llaman la atención del espectador y crean diferentes sensaciones en el interior y en el exterior de ellas, el uso de la plástica en cada uno de ellos en los que se ve reflejado el estilo de cada arquitecto, ya sean con formas curvas como es el caso de Hadid y Ghery o en formas imponentes y estructuradas con inclinaciones muy marcadas, como es el caso de Libeskind y Eisenman 
Por otro lado, cabe preguntarse si cestos edificios realmente cumplen con el propósito principal de la arquitectura (satisfacer las necesidades de los seres humanos) o ¿solo es producto de las excentricidades de los arquitectos? Y así mismo ¿Cómo se sienten los seres humano dentro y fuera de estas edificaciones?, a continuación se presenta una muestra de este movimiento arquitectónico (Ver figuras 1-4).

\section{Postura de lenguaje de patrones vivientes}

El lenguaje de patrones fue presentado por primera vez en 1977 por el arquitecto Christopher Alexander, el cual consiste en que cada ciudad y todo edificio están formados por ciertas entidades llamadas patrones, que surgen de ciertos procesos combinatorios. Esencialmente son como lenguajes, enfocados en la ciencia para comprender el mundo físico y emplean la
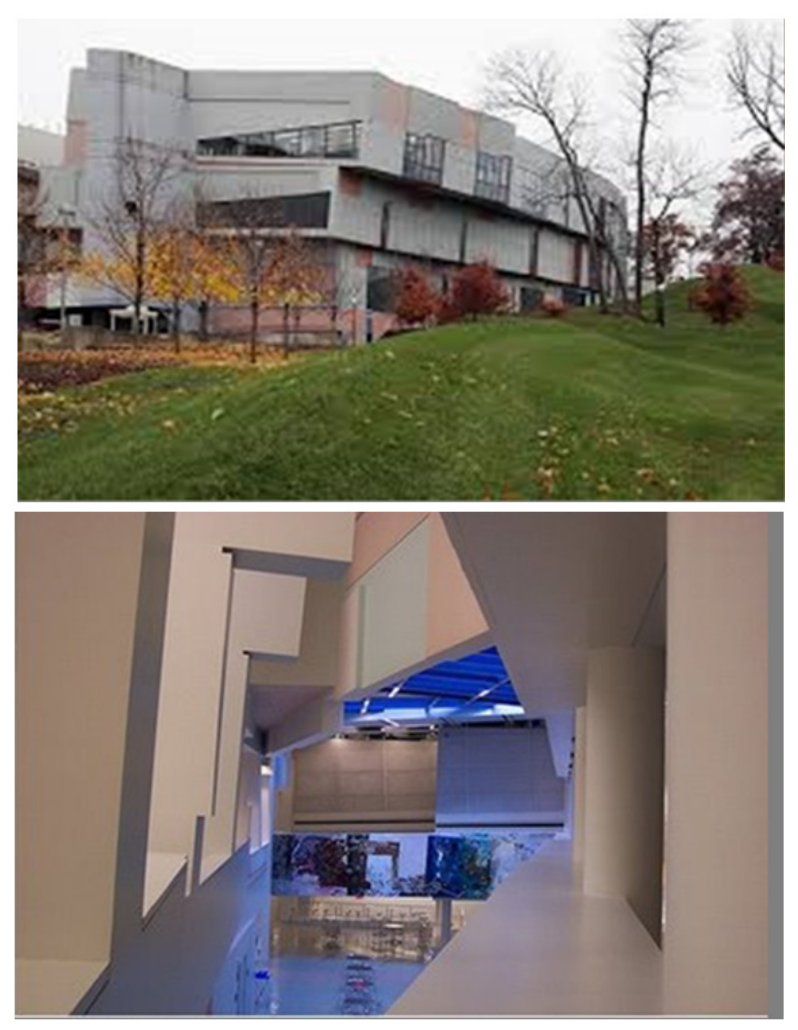

Figura 1. Imágenes de la arquitectura de Peter Eisenman. Aronoff Centre for Design and Art. Universidad de Cincinnati (1988 - 1993)

Fuentes: http://www.leungportfolio.com/ y http://www.taringa. net/post/info/8358253/Peter-Eisenman-en-Tokio-arquitectura.html respectivamente. tecnología solo como una herramienta más. Este lenguaje de patrones está orientado para originar una estructura viviente, y crear de esa forma una arquitectura que se conecte con la sensibilidad humana (Salíngaros 2004).

Según Stephen Grabow, citado por Salíngaros (2004), en su libro " Christopher Alexander: La búsqueda de un nuevo paradigma en arquitectura", basado en un movimiento arquitectónico que busca aplicar métodos científicos al problema de la forma arquitectónica, cree que la arquitectura más humana es aquella que antes que nada, se adapta a las necesidades del hombre.

Con respecto a lo anteriormente mencionado, Alexander en su texto "El modo intemporal de construir" expone, que se trata de un proceso a través del cual el orden de un edificio o de una ciudad surge directamente de la naturaleza interna de la gente, los animales, las plantas y las materias que los componen, lo que permite que la vida interior de un individuo, de una sociedad, - una ciudad florezca abiertamente en libertad. Así mismo afirma que estos lugares poseen una cualidad "viviente" en la medida de la habitabilidad que posean, generando así los patrones de acontecimientos, es decir que el carácter del lugar viene dado por los acontecimientos que allí ocurren, de tal forma, lo que cuenta en un edificio o en una ciudad no es su forma exterior o su geometría, sino los acontecimientos que en esta se generen. Todos estos patrones de acontecimientos van a depender de la cultura.

Adicionalmente explica el autor, que el patrón total, espacio y acontecimientos juntos es un elemento cultural. Es inventado por la cultura, transmitido por la cultura y está meramente anclado al espacio. Los patrones varían de lugar a lugar, de cultura a cultura, época en época... Pero aun así, en cada época y en cada lugar, la estructura de nuestro mundo está dada, por una serie de patrones que se repiten una, otra y otra vez. De tal forma, los patrones que conforman los edificios y las ciudades pueden estar vivos o muertos, pero, en la medida en que estén vivos dan rienda suelta a nuestra

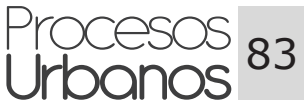



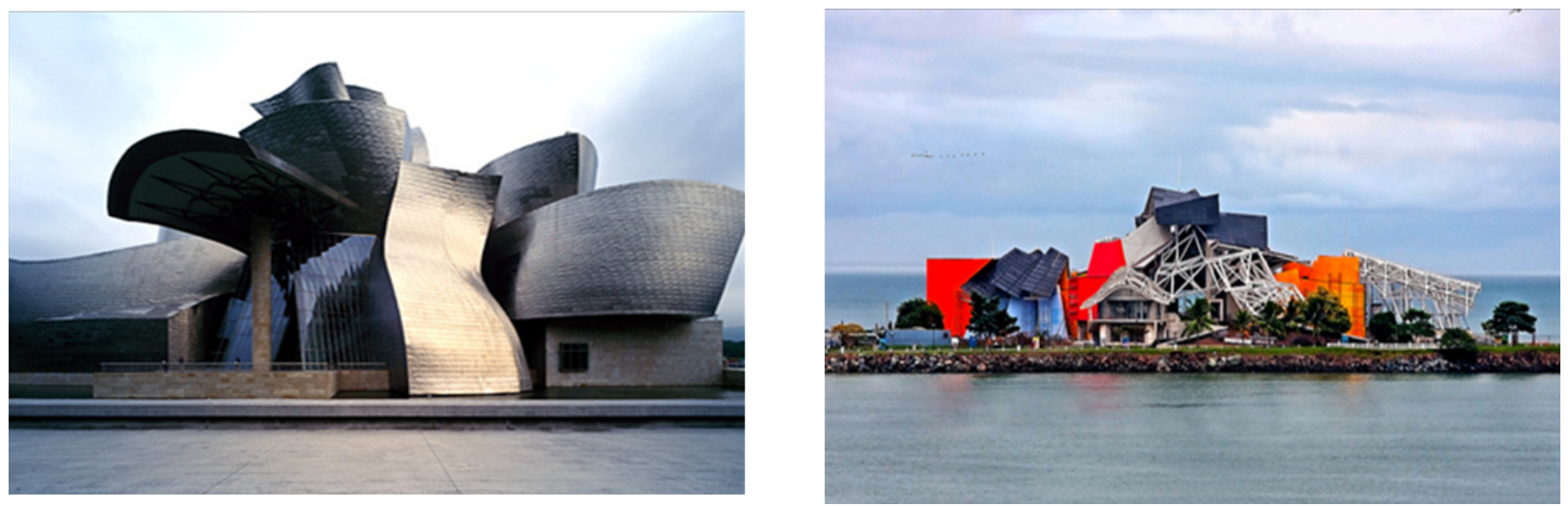

Figura 2. Imágenes de la arquitectura de Frank Gehry. Museo Guggenheim de Bilbao, Museo de Biodiversidad de Panamá.

Fuentes: http://www.euskalmuseoak.com/museo-guggenheim-bilbao/ $\quad y$

y http://panamacity.travel/es/place/panama-museum-of-biodiversity/ respectivamente
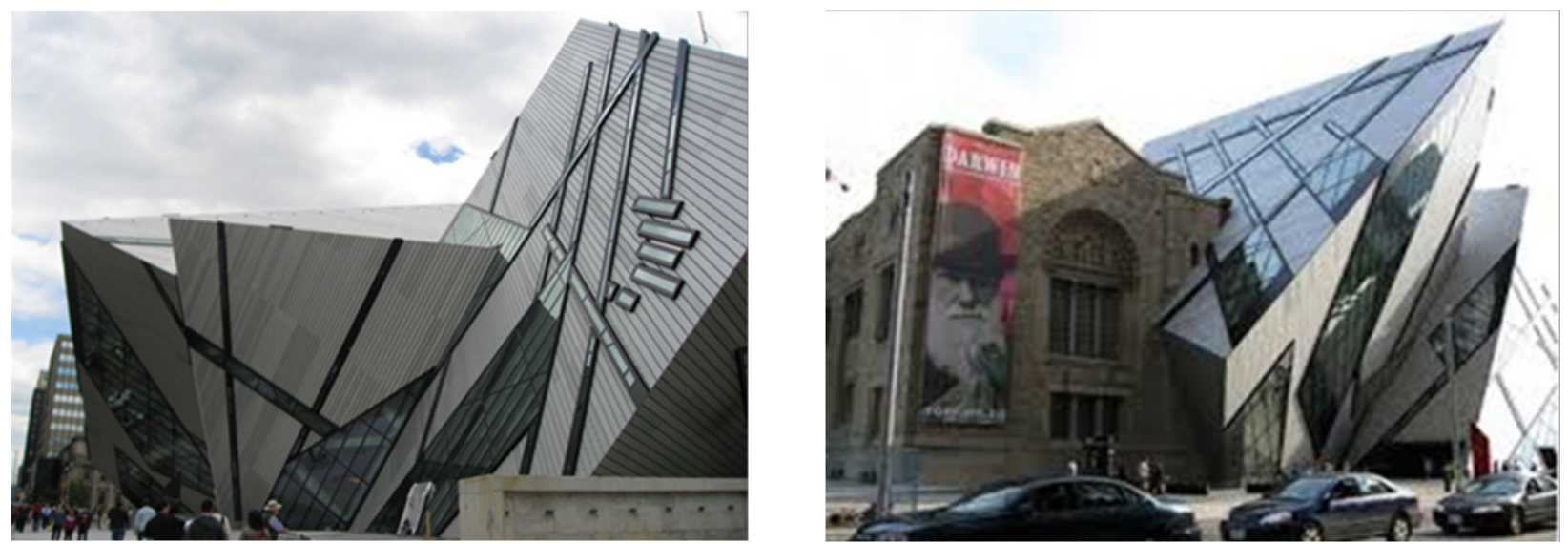

Figura 3. Imágenes de la arquitectura de Daniel Libeskind. Royal Ontario Museum (2007).

Fuentes: http://www.digitaljournal.com/article/282484 y https://www.thestar.com/life/homes/newinhomes35years/2012/05/11/torontos_architecture_ has_never_looked_better.html respectivamente.
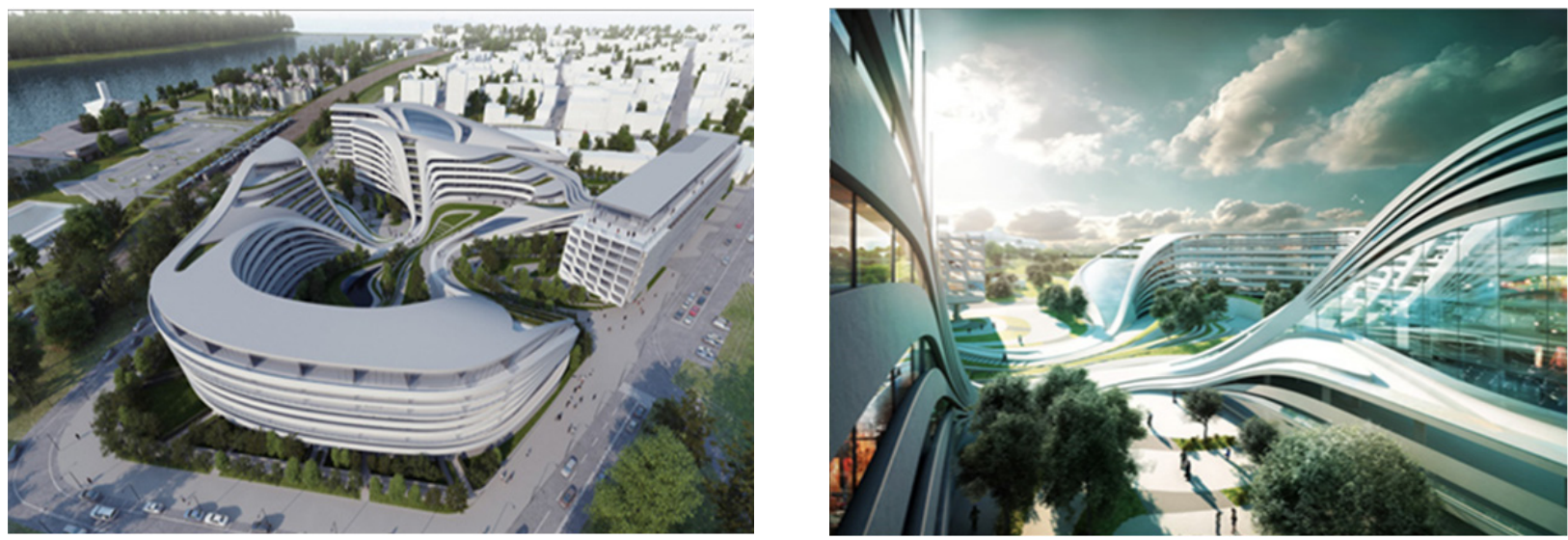

Figura 4. Imágenes de la arquitectura de Zaha Hadid. Proyecto Beko Masterplan.

Fuente: https://www.pinterest.com/pin/361413938822286911/ y https://www.pinterest.com/pin/454159943652632630/ respectivamente 
Sulbarán, J. - El fractal como paradigma arquitectónico.

fuerzas internas y nos liberan; en el caso de estar muertos nos encadena al conflicto interior, lo que quiere decir que los espacios arquitectónicos y urbanos son capaces de satisfacer emocionalmente a los habitantes y contribuir a su pleno desarrollo o por el contrario, pueden generar desequilibrio emocional y todo lo que esto conlleva.

Según Salíngaros (2004) la arquitectura y el planeamiento urbano se pueden entender como procesos que aumentan el grado de complejidad organizada. El acercamiento a los patrones urbanos como fractales enfatiza sus jerarquías relacionadas y la micro estructura. Así mismo explica que si no existe suficiente complejidad, la ciudad está muerta y si por su parte la complejidad no tiene suficiente organización, la ciudad se vuelve caótica e invivible. Recalca que los principios estructurales de la red urbana son los nodos, las conexiones y la jerarquía.

De igual modo menciona Salíngaros que las ciudades funcionan como fractales a medida que responden a las necesidades de los seres humanos a diferentes escalas, y por lo tanto, la importancia de las jerarquías de las conexiones, de las vías principales y sus conexiones con respecto a las secundarias; además afirma que al multiplicar las conexiones, los problemas de tráfico y la congestión de las vías, quedan suprimidos debido a que existirían más alternativas para transitar. Adicionalmente expresa que el grado de la organización de cualquier sistema complejo depende directamente del cociente entre el número de conexiones y el número de nodos.

Resumiendo lo anterior, se puede decir que el lenguaje de patrones, como postura fractal, intenta comprender y generar complejidad, comparte los principios básicos de la teoría fractal, la repetición, el uso de logaritmos, conectividad y adicionalmente generan satisfacción de los seres humanos a diferentes escalas, a través del estudio de sus culturas, el empleo de formas básicas familiares precisamente por su adaptabilidad a las sensibilidades humanas, con el propósito de concebir una arquitectura y un urbanismo que estén vivos (a través de la habitabilidad), apoyándose en los patrones de acontecimientos de los lugares, para lograr una armonía entre el ser humano y su entorno.

\section{LA HABITABILIDAD FRACTAL}

En los puntos anteriores se ha hablado de qué es un fractal y cuáles han sido las posturas más contradictorias con respecto a este nuevo paradigma, no obstante se ve necesario el estudio de la habitabilidad. Lo habitable implica insoslayablemente la relación entre los espacios arquitectónicos $y$ el hombre habitador. Los espacios arquitectónicos son medios necesarios y la satisfacción humana es el fin verdadero de la arquitectura (Ramírez. A, 2012)

Según Waldenfels, es el cuerpo el punto de giro y de anclaje que exige y que hace posible una revisión. No se puede pensar en habitar en el espacio sin una pertenencia intrínseca de los habitantes al lugar en que se encuentran, también afirma que el aquí marca un momento del enunciado; es así como el espacio habitado se centra en un aquí y un ahora corporal.

Tomando como base el concepto de arquitectura como contenedor de actividades humanas, según Ramírez, o el patrón de acontecimientos, como dice Alexander, por su parte Waldenfels lo completa diciendo, "al final, el espacio no es más que un contenedor, un esquema vacío, una pura extensio (extensión), cuya interioridad es compensada mediante una exterioridad reforzada. Podemos afirmar que la habitabilidad se ve directamente influenciada por la cultura de sus habitantes, patrones de comportamientos que varían de un individuo a otro, dependiendo de la sociedad a la que pertenezca, puede ser mayor o menor la diferencia, por lo tanto se está haciendo referencia a la diversidad.

La diversidad en la habitabilidad hace parte del comportamiento fractal de los seres humanos. Con base en que la habitabilidad y el espacio son indivisibles, toda habitabilidad se apoya en el tipo de espacio; estos forman una unidad: la arquitectura como un testigo presencial de los acontecimientos vividos (cotidianidad del ser humano habitador), por

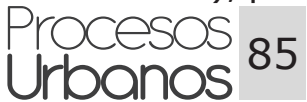


lo tanto su responsabilidad es proporcionar una habitabilidad más reconfortante y adaptable a las necesidades.

Según Ramírez. A:

La habitabilidad socio-cultural se refiere a la forma o el modo en que los espacios son habitados, a los modos de vida según tradiciones y costumbres ancestrales, y a las relaciones entre los hombres y los espacios que habitan. Estas relaciones le dan vida y contenido a lo que el arquitecto Villagrán llamaba, "la obra viva y habitada". En resumen, los arquitectos deben conocer las formas de habitar de las personas y de ellas interpretar los conceptos o requisitos cualitativos de los espacios a proyectar. En otras palabras, los arquitectos no inventamos los conceptos proyectuales, no dependen de nuestra "creatividad", sino de la correcta interpretación del habitar (2012, p. 9).

Tal como fue mencionado con anterioridad, la fractalidad es una de las características del comportamiento humano al igual que la complejidad. La individualidad de cada ser humano, va ligada a la incertidumbre, la ambigüedad (en relación sujeto/ objeto, orden /desorden, auto/ heteroorganización), las cualidades emocionales y sentimentales, entre otras (Morín 2004). Todas estas particularidades forman parte de cada ser humano el cual se ve relacionado directa e indirectamente con un mundo. Dicha complejidad se ve reflejada en la vida cotidiana de los seres humanos. La arquitectura no escapa de esta cotidianidad ya que ella actúa como un testigo presencial de los acontecimientos vividos, por lo tanto su responsabilidad es proporcionar una habitabilidad más reconfortante y adaptable a las necesidades.

Por último, Heidegger (1951) invita a reflexionar sobre el significado del habitar un espacio y la relación entre lugar- espacio y entre espacio- hombre, en el que el construir lugares genera espacios. Así como también del sentido arquitectónico de las construcciones, la esencia del arte de edificar para generar una construcción positiva, que tenga en sí la esencia del habitar, dándole a los espacios ya sean internos o externos, 86 Urocesos privados o públicos un significado, una esencia un sentido que les permita a los seres humanos sentirse identificados con dichos espacios, que les permita trascender en su propia dualidad de finitud- infinitud.

\section{CONCLUSIONES}

El cerebro humano al igual que el comportamiento, es considerado un fractal por su diversidad de pensamiento; muchos de sus comportamientos vienen siguiendo ciertos patrones que se repiten a diferentes escalas dependiendo de la magnitud de las decisiones o acciones que deben tomar en su cotidianidad, en esto viene incluido, la experiencia de ese ser y de sus antecesores, por lo tanto, el comportamiento de los individuos en una sociedad puede ser parecido, pero no el mismo, así como hay patrones semejantes, existe la conexión entre los seres humanos, con la sociedad y el ambiente, tema que se ve ampliado en la actualidad debido a las nuevas tecnologías y la globalización.

Sin duda, los grandes iconos de la arquitectura contemporánea a nivel mundial cuentan con un dominio realmente impresionante en el uso de la geometría de las formas, ya sean apoyados en las nuevas tecnologías, en equipos numerosos de profesionales expertos en programas y herramientas computacionales, quienes crean edificios que prácticamente pueden ser considerados obras de arte, pero tal como una obra de arte no depende del museo o del contexto donde será exhibida, estos edificios también, rompen por completo con los estilos tradicionales que muchas veces los rodean. En síntesis, el comportamiento de dichos arquitectos asemeja a una rebeldía o irreverencia, donde compiten los unos con los otros, para ver quién puede crear algo aún más llamativo, abstracto. Muchas veces parecieran no considerar a los habitadores de esos espacios; su percepción aparenta ser la única forma que existe, tal como en la ciencia clásica su arquitectura sugiere que "todos los hombres" son iguales y que por consiguiente tienen las mismas percepciones, las mismas corporeidades, la misma forma de habitar, cosa que no es cierta y precisamente la fractalidad y la nueva ciencia comprende que 
lo más importante es el estudio de los seres humanos y su diversidad de realidades, sus culturas, su cotidianidad entre otros aspectos que han acercado a la ciencias humanas en el conocimiento.

Por lo tanto, el asumir una postura fractal en la arquitectura conlleva más allá que la variable formal de las edificaciones y las ciudades. Esta no depende únicamente de las formas geométricas ostentosas que muchas veces son egoístas, tanto con el contexto como con el usuario de dicha arquitectura. La geometría compleja debe tener inmersa en esa complejidad la forma de habitar los seres humanos, adaptándose a las diferentes funcionalidades, requerimientos y formas de habitar los espacios, no se puede olvidar que la arquitectura es la encargada de acompañar, apoyar y servir al habitante, por lo tanto, debe incurrir en detalles que la lleven a propiciar un pleno desarrollo de las capacidades de los seres humanos.

Se podría decir entonces que para concebir el diseño y construir una arquitectura fractal que promueva esa diversidad de los seres humanos hay que tomar en cuenta, primeramente la cultura local, haciendo un estudio socio cultural donde se coloque especial jerarquía en la observación de esos patrones de comportamientos de los habitantes; dicho estudio debe ser concebido por un equipo integrado por los diferentes profesionales y actores, sin olvidar la participación ciudadana que puede determinar esa pertinencia y trascendencia de los espacios. A pesar de vivir en un mundo tan globalizado, los países latino americanos no están en condiciones ya sean económicas o de pensamiento crítico, para aceptar los paradigmas que están enfrentando los países del tan llamado primer mundo; esto viene dado por esa misma mezcla de culturas que representa a los latinos que se ve influenciada por esas culturas tan diversas y que engrandece y complejiza ese conjunto de patrones de comportamiento.
Seguidamente, es importante por lo anteriormente mencionado acerca de lo complejo de la diversidad, que es determinante entonces esa relación del ser humano-ambiente y espacio - ser humano. En estas dos relaciones se establece un conocimiento mayor de la forma de habitar: siempre debe ser enfocado en un lugar determinado sin dejar de lado esa relación global -local y viceversa, aquí es donde se puede observar esa complejidad de que habla Morín, por que como bien dice Waldenfels, la buena arquitectura es la extensión del ser humano que la habita.

Otro punto importante es el uso de esas formas geométricas familiares que pueden ser establecidas con el mismo estudio socio cultural, donde se puedan determinar cuáles son las preferencias visuales y perceptivas, que van a ser estipuladas por ese contexto local, y por último, el empleo de espacios flexibles que permitan a los habitantes distribuir y apropiarse de los espacios a su propio ritmo de vida.

Ramírez. A (2012, p. 5), basado en Hegel, Villagrán y Arai, afirma que "los objetos arquitectónicos son simples medios que no tienen su fin en ellos mismos". Su finalidad está más allá y consiste en satisfacer necesidades espaciales humanas.

Por tales razones, queda claro que la arquitectura, ya tenga la singularidad de "fractalidad" y no su principal objetivo, siempre debe ser en beneficio de los seres humanos, por lo tanto indistintamente de su forma, su función siempre debe centrarse en satisfacer las necesidades de sus habitantes y por eso la importancia de la diversidad cultural-corporal-espacial, apoyada en los conocimientos científicos, la experiencia, la cultura y el estudio de los habitantes de estos espacios, son aspectos primordiales para lograr un mejor resultado en la aproximación arquitectónica . 


\section{REFERENCIAS}

Alexander, C. (1981). El modo intemporal de Construir. Barcelona- España, Editorial Gustavo Gili, S.A

Heidegger, M (1951). Construir, Habitar, Pensar. Recuperado de: http://www.laeditorialvirtual. com.ar/pages/heidegger/heidegger construirhabitarpensar.htm acceso abril de 2016.

Jencks, C. (2003). El nuevo paradigma en arquitectura. Architectural Review, 02, 2003.

Martín, V. (2008). Desafíos actuales de la Ética aplicada. Uniojeda Fondo Editorial de la Universidad Alonso de Ojeda, Costa Oriental del Lago, Maracaibo, República Bolivariana de Venezuela.

Morín, E. (2004). Introducción al pensamiento complejo. México, Editorial Gedisa.

Pineda, E. (2009). Plan urbano, morfología fractales. Tesis doctoral. Universidad de Zulia, Venezuela.

Ramírez, A. (2012). La Habitabilidad. Recuperado de: http://www.dtic.upf.edu/ rramirez/Arponce/ LaHabitabilidad.pdf acceso marzo de 2016.

Reyes, E. (2005). Breve introducción a Jacques Derrida y la deconstrucción. Recuperado de http://hipercomunicacion.com/pubs/derrida-decons. html acceso marzo de 2016.

Salíngaros, N. (2004). La soledad del Arquitecto. Recuperado de: http://www.google.co.ve/l?sa$=$ t\&rct $=j \& q=\& e s r c=s \&$ source $=$ web\&cd $=5 \&$ ved $=0$ CEOQFjAE\&url $=h$ http $\% 3 A \% 2 F \% 2 F a r e d i$. net78. net\%2Fperu\%2F0intro\%2Fantidec. doc\&ei=79BiU6r3EIqmyAT4nYL4CA\&usg=AFQjCNH7Hh6Tqm4crE7qM2zH_1tte0enkw\&sig2=DEIYPLcj| 5KVmAZVMs8bg acceso febrero de 2016.

Salíngaros, N. (2005). Principles of Urban Structure. Design Science Planning. Recuperado de: http://www.arqchile.cl/publicacion7 teoria red urbana.htm acceso marzo de 2016. 